\title{
Serum and secretory antibody responses to Neisseria gonorrhoeae in patients with gonococcal infections
}

\author{
P. TAPCHAISRI AND S. SIRISINHA \\ Department of Microbiology, Faculty of Science, Mahidol University, Bangkok, Thailand
}

\section{Summary}

The present study was conducted to characterize the nature and pattern of serum and secretory antibody responses to $N$. gonorrhoeae by haemagglutination inhibition, opsonization, and immunofluorescence techniques in male and female patients with different clinical manifestations of gonorrhoea. Most male patients with acute gonococcal infection developed serum IgG and, less frequently, IgM antibodies against pilated gonococci within 2 weeks of infection and these antibodies declined to normal levels 1 to 2 months after treatment. This response was not noticeably different from the responses developed in male patients with subacute infection and female patients with chronic infection.

Immunological analyses of the seminal plasmas and cervical fluids from these patients showed that antibodies reactive with both pilated and non-pilated $N$. gonorrhoeae are present in some of the cases. A small percentage of male patients who recovered from subacute gonococcal infection but not from acute infection possessed low levels of $\mathrm{IgG}$ and, less frequently, IgA antibodies to gonococcal antigens in their seminal plasmas. In contrast, more than half of the females with gonorrhoea had IgG antigonococcal antibodies in the cervical fluid. However, a small number of samples also showed the presence of $\operatorname{IgA}$ and $\operatorname{IgM}$ antibodies. IgA antibody in most of these IgA-positive samples was of the secretory type. The presence of secretory $\operatorname{IgA}(\mathrm{SIgA})$ in secretions and the lack of correlation between the antibody titres in serum and in secretions of these patients suggest that infection with $N$. gonorrhoeae may independently stimulate both a systemic and a local humoral immune response.

\section{Introduction}

Although information regarding the biology of $N$. gonorrhoeae has increased rapidly during the last decade, relatively little is known about the pathogenesis of this organism and the role of host defence in controlling the disease process. The virulence of

Received for publication June 2, 1976

Address for reprints: Dr S. Sirisinha, Department of Microbiology, Faculty of Science, Mahidol University, Rama VI Road, Bangkok 4, Thailand gonococci is associated with formation in vitro of specific colony types (Kellogg, Peacock, Deacon, Brown, and Pirkle, 1963). While the virulent gonococci from colony types $\mathrm{T} 1$ and $\mathrm{T} 2$ possess pili on their surface, the avirulent organisms $T 3$ and $T 4$ do not possess these surface appendages (Jephcott, Reyn, and Birch-Andersen, 1971; Swanson, Kraus, and Gotschlich, 1971). Several lines of evidence indicated that pili played an important role in the pathogenesis of gonorrhoea by enabling the organisms both to attach to the epithelium and to evade the host's phagocytic defence (Blake and Swanson, 1975; Ofek, Beachey, and Bisno, 1974; Punsalang and Sawyer, 1973). The ability of the host to mount an effective immune response to these surface components may therefore confer a certain degree of protection against re-infection by $N$. gonorrhoeae. Female patients with gonorrhoea developed serum and secretory IgA antibodies during the course of infection (O'Reilly, Lee, and Welch, 1976). The present studies were conducted to characterize further the nature of serum and secretory antibody responses in male and female patients with different clinical manifestations of gonorrhoea.

\section{Material and methods}

\section{Bacteria}

All four colony types of $N$. gonorrhoeae strain F62 were provided by Dr. D. S. Kellogg, Jr (Center for Disease Control, Atlanta, Ga, U.S.A.). Local strains of gonococci were isolated from male patients with acute gonococcal infection. Procedures for growth, maintenance, and preparation of bacterial suspensions have been reported (Punsalang and Sawyer, 1973). Organisms from T1 colonies from eleven local isolates were found to be antigenically indistinguishable from the prototype F62T1 when reacting with the corresponding serum from the patients in haemagglutination inhibition, opsonization, and immunofluorescence tests, and the absorption of these sera with T1 and not T4 from the homologous strain abolished all activities against F62T1. The latter was therefore used throughout these studies except when otherwise indicated.

\section{Subjects}

Serum, seminal plasma, and cervical fluid were obtained from persons aged 18 to 48 years who were grouped as follows:

(1) Male patients This group consisted of patients with gonococcal urethritis infection who came to the Student Health Center of the Faculty of Science, Mahidol University, Bangkok, Thailand, for treatment. They all had 
positive results to cultures made using GC medium base (Difco) containing 1 per cent. haemoglobin, 5 per cent. horse serum, and 1 per cent. VCN inhibitor. They were arbitrarily divided into acute and subacute groups according to the medical history.

Patients with acute infection were those who had been exposed to a possible source of infection within 1 week and had signs and symptoms of infection appearing 1 to 4 days before attending the clinic. This group of patients had had no drug treatment before coming to the Center.

Patients in the subacute category were those who recalled having had contact with a possible source of infection more than 1 week before attending the clinic. These patients noticed signs and symptoms of infection 5 to 30 days (average 14) before seeking medical treatment and some gave a history of inadequate self treatment.

None of the patients had a second contact after signs and symptoms of the current infection appeared. Both groups of patients received similar drug treatment, $2 \mathrm{~g}$. ampicillin and $1 \mathrm{~g}$. probenecid orally for 2 successive days. All were judged by the disappearance of symptoms and signs and nine by negative cultures to have been cured by this regimen of antibiotic treatment.

(2) Female patients These patients were those attending the Out-Patient Department of Bangrak Hospital in Bangkok for problems concerning the urogenital system. Diagnosis of gonorrhoea was made only when a positive culture for gonococci, using the media described above, was obtained from vaginal, urethral, or rectal swabs. Diagnosis of diseases other than gonorrhoea was based on clinical and/or laboratory findings.

(3) Normal controls This group of subjects comprised healthy male and female university students who denied any previous history of gonorrhoea.

\section{Collection of specimens}

Serial blood samples taken throughout the course of infection were available from eleven male patients with acute infection. Samples were taken from these patients before drug treatment (day 1) and again 3, 5, 7, 14, 28, and 60 days later. Samples were taken from those with subacute infection on days 1, 7, and 14 only. Female patients were bled only once on the day of their first visit to the hospital. Blood was drawn by venepuncture, and the serum was stored at $-20^{\circ} \mathrm{C}$.

Seminal plasma was obtained from the patients as soon as possible after they were judged to have been cured, usually 3 to 5 days after treatment was initiated, and again $7,14,28$, and 60 days later. The semen was collected by masturbation, allowed to liquefy for 15 to $20 \mathrm{~min}$. at $26^{\circ} \mathrm{C}$, and the seminal plasma obtained after centrifugation was stored at $-20^{\circ} \mathrm{C}$.

Cervical mucus was collected on the patient's first visit to the hospital ; serial samples of cervical mucus were available from some of these patients. The mucus secretion was collected and processed as described by Tjokronegoro and Sirisinha (1975). All secretions, regardless of the volume obtained, were suspended in $1 \mathrm{ml}$. 0.85 per cent. $\mathrm{NaCl}$ (saline). The suspension was mixed thoroughly and centrifuged, and the supernatant fluid, referred to as cervical fluid, was stored at $-20^{\circ} \mathrm{C}$. The protein content of all cervical fluid samples was determined by FolinCiocalteau tyrosine method (Lowry, Rosebrough, Farr, and Randall, 1951) using human albumin as a reference standard. The concentration of protein in these fluids varied from less than $10 \mathrm{mg} . / 100 \mathrm{ml}$. to as high as $480 \mathrm{mg}$./ $100 \mathrm{ml}$. Because it was found from the preliminary analysis that antibody activity was not detectable in the cervical fluid that has less than $22 \mathrm{mg}$. total protein $/ 100 \mathrm{ml}$., all samples with a protein concentration lower than this value were discarded.

\section{Absorption of serum, seminal plasma, and cervical fluid}

Absorption of serum, seminal plasma, and cervical fluid samples with gonococci was performed as previously described (Punsalang and Sawyer, 1973). Removal of SIgA antibody from seminal plasmas or cervical fluids was achieved by absorbing the latter with antiserum specific for the secretory component of SIgA as described by Tjokronegoro and Sirisinha (1975).

\section{Immunofluorescence (IFA)}

Unfixed bacteria were used as the test antigen in indirect fluorescent antibody technique (Welch and O'Reilly, 1973) employing monospecific fluorescein-conjugated antisera to human $\operatorname{IgG}, \operatorname{IgM}$, and $\operatorname{IgA}$. Appropriate positive and negative controls were always included in all experiments. The results were highly reproducible, as the same reactive serum used as control gave essentially the same antibody titre when repeatedly tested on different occasions. Antibodies detected by this method appeared to be directed to both the pilar and the somatic antigens of gonococci as absorption of the serum with non-pilated organisms also partially eliminated antibody activity against pilated gonococci. Most normal sera tested (56 males and 38 females) gave negative fluorescence; those that were positive had detectable IgG and/or IgM antibody with titres rarely exceeing $1: 2$. These 'natural' antibodies could be completely absorbed with either $\mathrm{T} 1$ or $\mathrm{T} 4$ gonococci.

\section{Haemagglutination inhibition test (HAI)}

The technique employed was similar to that of Punsalang and Sawyer (1973), except that a 1 per cent. suspension of human group $\mathrm{O}, \mathrm{Rh}$-positive red blood cells was used instead of rabbit red blood cells. Human red cells were used as they were more readily available, and their use avoided the non-specific clumping of rabbit cells which occurs occasionally with human serum. Rabbit red cells also frequently autoagglutinate. The test was specific for pilated gonococci, as less than 20 per cent. of the 94 normal sera examined gave a positive result and the titre of these positive sera rarely exceeded $1: 2$. Normal serum with negative HAI titre was used as control. The HAI titre of the same positive serum varied within one 2-fold dilution when tested on different occasions.

\section{Opsonization (OP)}

Phagocytosis of gonococci was measured in a 'dilute' phagocytic test system (Punsalang and Sawyer, 1973). Rabbit exudative polymorphonuclear leucocytes (PMN) were used instead of human PMN because the former are more readily available and the results of the two were indistinguishable from each other. The serum had to be diluted 1:16 before testing to reduce clumping which

«Hyland Division Travenol Laboratories, Inc., Costa Mesa, Calif., U.S.A. 
occasionally interferes with the phagocytic process. The diluent used consisted of a modified Hanks's solution containing 0.01 per cent. bovine plasma albumin, 0.1 per cent. glucose, and 1:16 fresh normal serum. The baseline value of phagocytosis of $\mathrm{F} 62 \mathrm{~T} 1$ in the presence of diluent alone varied between 8 and 16 per cent. Opsonization was considered to have occurred if phagocytosis in the presence of reactive serum was at least twice as high as that of the baseline value. Using this criterion, none of 94 normal sera tested gave positive OP test. Positive serum was always included in all experiments.

\section{Results}

Serum antibody response in male patients with acute gonococcal infection

Antibody response in male patients with acute gonococcal infection was investigated by following the change of serum antibody titres throughout the course of infection. Antibodies reactive against T1 from homologous local isolates (HST1) were determined in serial blood samples by HAI, OP, and IFA techniques. A minimum of a 4-fold increase in HAI and IFA titres or a positive OP test at a dilution of $1: 16$ or higher was chosen as a criterion for an antibody response. The results presented in Fig. 1 were analysed according to whether the present illness was a primary or a repeated infection. The pattern of serum antibody response was similar in these two groups of patients except that a higher proportion of the patients in the latter group ( $86 \mathrm{per}$ cent) showed a significant antibody response which was primarily associated with IgG antibody. In addition, the magnitude of increase of IgG antibody titre, by IFA technique, in those with repeated infection was in general higher than in those with

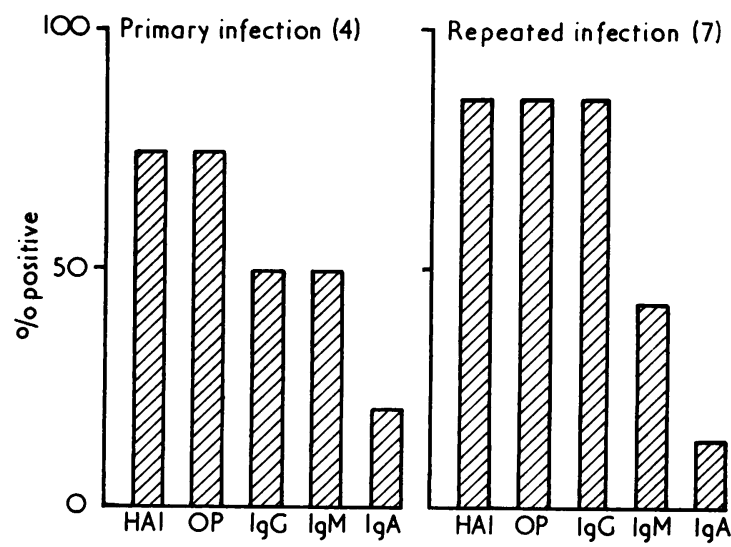

FIG. 1 Serum antibody response to HST1 in male patients with acute gonococcal infection. IgG, IgM, and Ig $A$ antibodies determined by IF $A$ technique, employing antiserum specific for the individual immunoglobulin class. Total number of patients in each category shown in parenthesis primary infection; the geometric mean ${ }^{\star}$ in the former was 1:20 compared with $1: 10$ in the latter. The peak of antibody titres for both groups was attained 7 to 17 days after infection and started to decline towards the pretreatment level 1 to 2 months after treatment was initiated. The combined data showed the geometric means of the peak titres to be $1: 11$ for HAI, $1: 30$ for OP, $1: 15$ for IgG, $1: 9$ for IgM, and $1: 4$ for IgA. The typical changes of the serum antibody titres during the course of acute gonococcal infection in patients with primary infection and in those with repeated infection are shown in Fig. 2.

Serum antibody response in male patients with subacute gonococcal infection

All sera obtained from fourteen male patients with subacute gonococcal infection were analysed for antibodies as previously described for those with acute infection, except that F62T1 was used instead of HST1 in the test system. Also, because only one to three serum samples were available from each patient in this group, the criterion for a positive response was modified from that used in the acute group, i.e. a response was considered to have occurred if a serum sample had positive HAI activity at $1: 8$, OP activity at $1: 16$, or IFA activity at $1: 16$ for IgG and IgM, and 1:4 for IgA. On the day of treatment (day 0 in Fig. 3), as high as 80 per cent. of the patients showed positive antibody response. This value was considerably higher than the 36 per cent. observed in patients with acute infection on the day of treatment when the same criteria were used. IFA analysis showed antibodies in these patients were associated mainly with $\operatorname{IgG}$ (71 per cent.) and to a lesser extent with IgM (14 per cent.) and IgA ( 7 per cent.). The geometric means of the antibody titres on day 0 were $1: 7$ for HAI, 1:22 for OP, 1:19 for IgG, $1: 3$ for IgM, and 1:3 for IgA. Antibody titres in these patients remained at approximately the same levels when tested again 7 and 14 days after the treatment was initiated (Fig. 3). These antibodies were specific for the pilated gonococci as they could not be eliminated after absorbing the serum with $N$. catarrhalis. In contrast to this, antibody activity in those normal sera that gave positive IFA test with $N$. gonorrhoeae could be completely eliminated when they were similarly absorbed.

Antigonococcal antibodies in seminal plasma of patients with gonococcal infection

53 seminal plasmas from eleven patients recovered from acute gonococcal infection, 37 samples from fourteen patients in the subacute group, and fifty samples from fifty normal individuals were tested for the presence of antibodies against $N$. gonorrhoeae by HAI, OP, and IFA. Whereas none of the seminal plasmas from normal individuals and from patients

^Geometric means were calculated from positive samples 


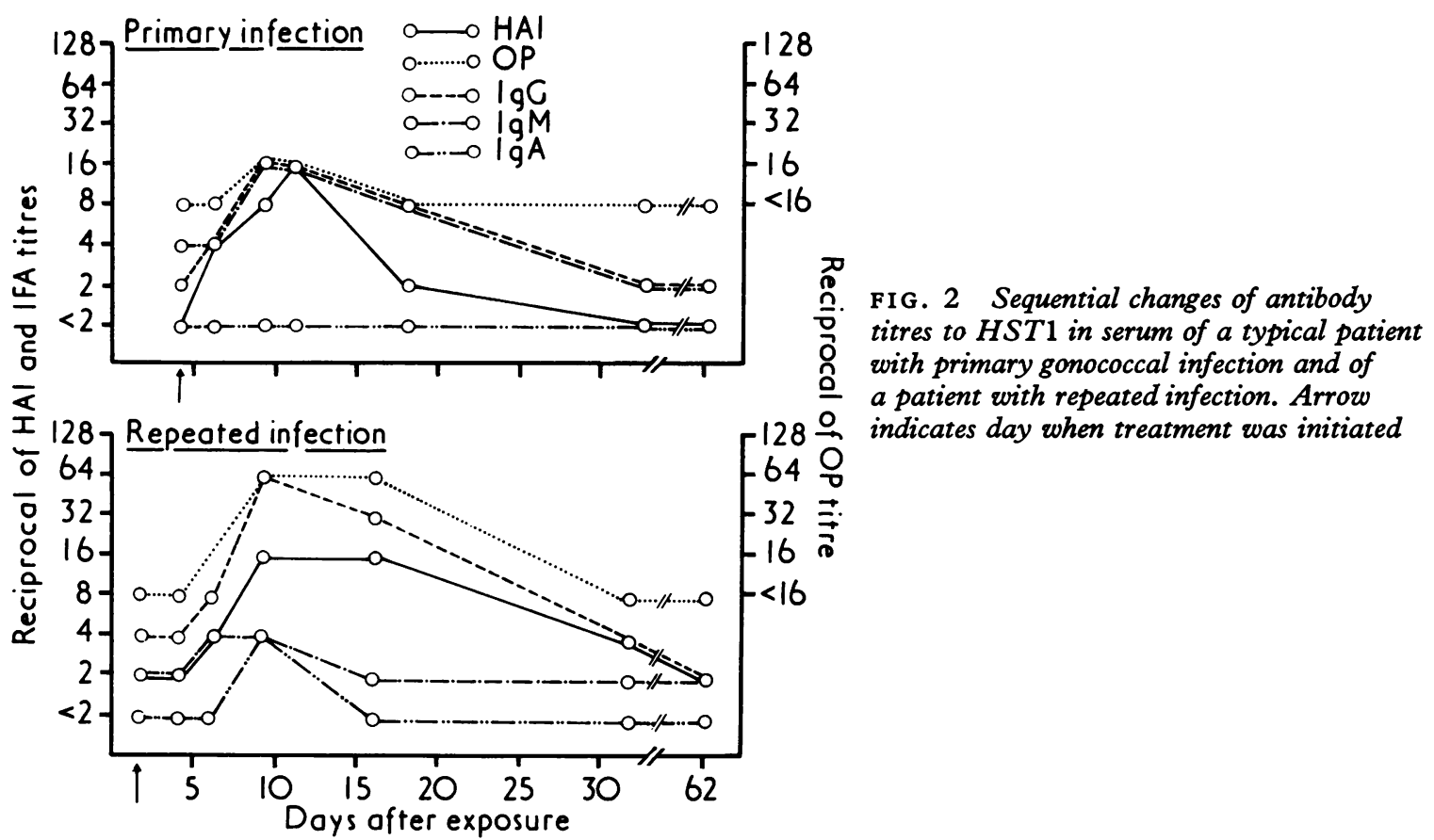

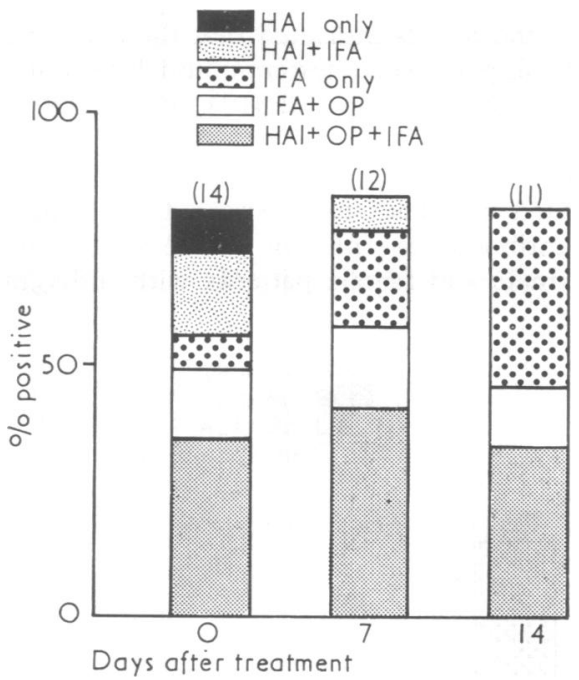

FIG. 3 Antibody response in serum of male patients with subacute gonococcal infection. Antibody titres determined by $H A I, O P$, and IF $A$ techniques, using F62T1 as test antigen. Total number of sera tested shown in parenthesis

with acute infection had detectable antibody to F62T1 when tested at $1: 2$ dilution, some specimens from patients in the subacute group were found to have low IgG and/or IgA antibody titre by IFA (1:4 or less). However, unlike the serum antibodies which persisted for at least 2 to 3 weeks after treatment, antibodies in most seminal plasmas declined to an undetectable level in less than 1 week after the treatment was initiated (Fig. 4). In contrast to the corresponding sera, these specimens reacted equally well with organisms from either T1 or T4 colonies, and these activities could be completely removed by absorbing the secretions with organisms from either colony types. The activity in seminal plasmas was associated primarily with IgG. The IgA antibody, which was detected in only two samples, was of the secretory type as the antibody activity disappeared after absorbing them with antiserum to human secretory component.

Antigonococcal antibodies in serum and cervical fluid of female patients with diseases of urogenital system 146 sera and 284 cervical fluids were obtained from 223 female patients. Paired serum and cervical fluid samples were available from 146 patients. In contrast to the results in the male patients whose serum opsonic activity was determined at several serum dilutions, the opsonic activity against F62 T1 in the serum of female patients was tested only at 1:16 and the results were recorded as either positive or negative from this one determination. More than 90 per cent. of the serum samples from female patients with a definite diagnosis of gonorrhoea had detectable antigonococcal antibody by at least one of the three methods used (Fig. 5) and these activities could not be eliminated after absorption with $N$. catarrhalis. As in the male patients, serum antibodies in the females were found to be associated almost exclusively 


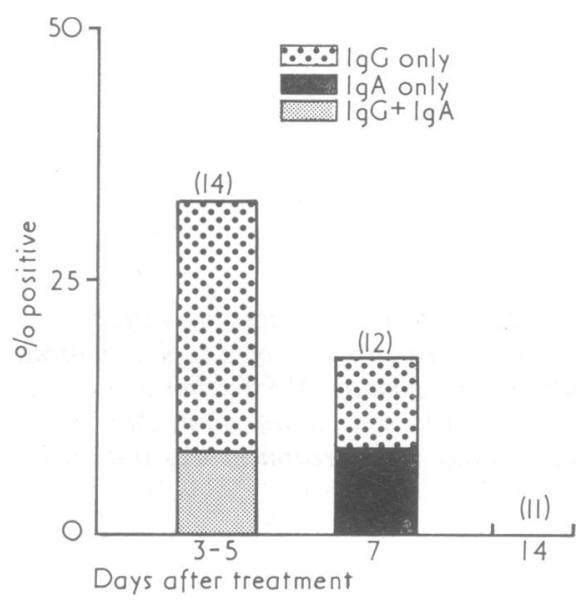

FIG. 4 Antigonococcal antibodies in seminal plasma from male patients with subacute gonococcal infection. Antibodies detected by IFA technique using F62T1 as test antigen. Total number of seminal plasmas tested shown in parenthesis

with IgG (88 per cent. for IgG, 2 per cent. for $\operatorname{IgM}$, and 2 per cent. for $\operatorname{IgA}$ ). The geometric means of the serum antibody titres in the females with gonorrhoea were $1: 8$ for HAI, 1:33 for IgG, 1:3 for IgM, and $1: 2$ for IgA. The titre of serum IgG antibody in the female patients was as a group higher than in the male patients. On the other hand, almost half of the fifteen healthy females analysed also gave a positive result for antigonococcal antibodies, mainly by the IFA technique with a geometric mean titre of $1: 9$ for IgG. Similarly, about one-third of the patients with other

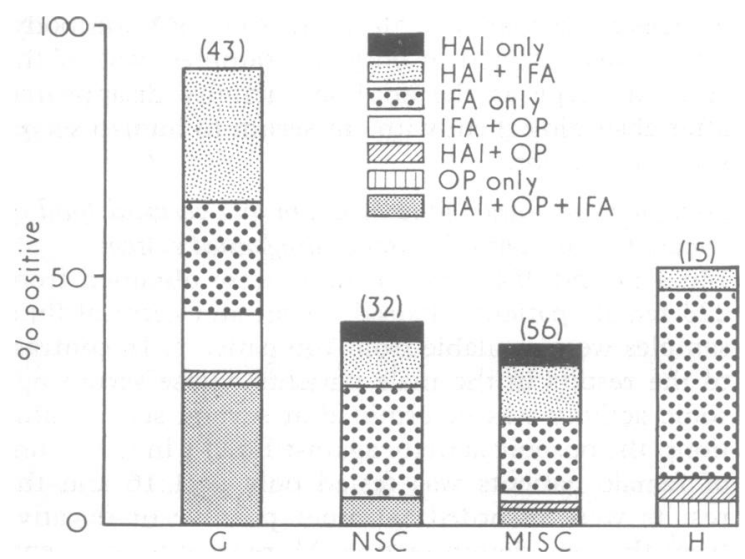

FIG. 5 Antigonococcal antibodies in serum of female patients with diseases of urogenital system. Antibodies determined by HAI, OP, and IF A techniques, using F62T1 as test antigen. Number of patients in each category shown in parentheses. $G=$ gonorrhoea, NSC = non-specific cervicitis, $M I S C=$ miscellaneous (candidiasis, syphilis, trichomoniasis, etc.), $H=$ healthy diseases of the urogenital system also exhibited positive IFA reaction with the geometric mean of the IgG titre of $1: 8$.

Although none of the cervical fluids tested had positive HAI, or OP activity for F62T1, some specimens had detectable IgG, IgM, and/or IgA antibodies by the IFA technique. Approximately 60 per cent. of the cervical fluid taken during the first visit to the hospital from females with a definite diagnosis of gonorrhoea possessed antibody when tested with either F62T1 or F62T4 (Fig. 6). SIgA was detected in more than half of the IgA-positive samples as evident from the disappearance of antibody activity after removal of SIgA by absorption with antiserum to human secretory component. Antigonococcal antibodies in the cervical fluids of patients with other illnesses were detected at much lower frequency (Fig. 6). In contrast to the results from patients with a definite diagnosis of gonorrhoea, antibody detected in other groups of patients was exclusively of the IgG class and no IgA response could be detected by IFA. Antigonococcal antibody was never detected in the cervical fluid from healthy females.

The relationship between serum antibody and antibody in the cervical fluid obtained at the same day was analysed by determining antibody activity in the paired samples from 43 females with gonorrhoea. $\chi^{2}$ analysis of the results indicated that there was no direct relationship between systemic and local antibodies in these patients $\left(\chi^{2}=2 \cdot 3194 ; P>0.05\right)$.

\section{Discussion}

Data presented in this study showed that antigonococcal antibodies are present in the serum and secretion of male and female patients with different

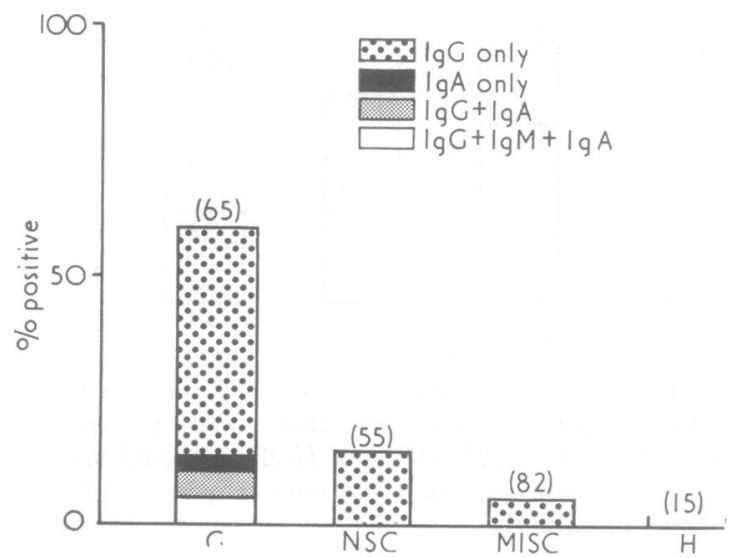

FI G. 6 Antigonococcal antibodies in cervical fluid of female patients with diseases of urogenital system. Antibodies determined by IFA technique using F62T1 as test antigen. Total number of cervical fluids tested shown in parenthesis. See legend to Fig. 5 for abbreviations 
clinical manifestations of gonorrhoea. Because two of the methods used, namely HAI and OP, depend on the interaction between pili an anti-pilar antibodies (Punsalang and Sawyer, 1973), it appears that these serum antibodies are directed against this virulence factor of gonococci. The antibodies detected by these two methods are different from the natural antibodies which could be found at low level by IFA because the latter are directed mainly against the somatic antigens of $N$. gonorrhoeae.

Our data confirmed and extended the work of Buchanan, Swanson, Holmes, Kraus, and Gotschlich (1973) that anti-pilar antibodies can be demonstrated in the serum of patients with gonococcal infection. These investigators reported that the serum antibody response was detected in the females but was not frequently detected in the males. Our data, which were mainly from male patients, disagree with the above observation as it was found that the serum antibody responses in male and female patients were similar. Detailed analysis of the data from these male patients suggested that, if there was an immunological memory following recovery from previous infection, it was of a short duration only as there was no marked difference in the response between those with primary infection and those with repeated infection (Fig. 1). In both groups, the antibody levels reached the peak within 2 weeks of exposure (Fig. 2). Cohen, Kellogg, and Norins (1969) reported that serum antibodies against heat-labile antigens of $N$. gonorrhoeae attained the peak level 5 to 10 days after experimental intraurethral gonococcal infection in male volunteers. The time required for the antigonococcal antibodies in these volunteers to decline to normal level was 2 to 3 months. The slight difference in the duration of increased antibody level reported by different investigators (Buchanan and others, 1973; Cohen and others, 1969; O'Reilly and others, 1976) may be due to the time when treatment was initiated in different groups of patients.

The results from the analyses of seminal plasmas and cervical fluids showed that antibodies to $N$. gonorrhoeae were present in some secretions from these patients and this confirmed and extended the finding of O'Reilly and others (1976) who found IgA antibody reactive with $T 1$ gonococci in the vaginal wash of females with gonorrhoea. However, these investigators analysed only the IgA antibody response. In the present study, other classes of antigonococcal antibodies were also analysed and it was found that the predominant antibody reactive against gonococci in these patients was IgG and not SIgA. One possibility for the failure to detect SIgA as the main antibody in the secretions from these female patients is that $N$. gonorrhoeae may have destroyed SIgA before it could be analysed. Plaut, Gilbert, Artenstein, and Capra (1975) demonstrated that $N$. gonorrhoeae secreted extracellular enzymes that were capable of specifically destroying IgA. However, the finding of IgG antibody in the cervical fluid of females is not entirely unexpected, as several groups of investigators reported that, in contrast to other secretions in which SIgA predominates, the predominant immunoglobulin in secretions of reproductive system was IgG (Chipperfield and Evans, 1975; Herrmann and Hermann, 1969; Masson, Heremans, and Ferin, 1969; Tjokronegoro and Sirisinha, 1975).

The higher frequency of detecting antibody in the secretions of female patients may be due to the fact that infection (in females) is more difficult to detect, so that females have a higher chance of prolonged antigenic stimulation than males in whom early diagnosis and treatment may have abrogated local stimulation. A higher frequency of finding antibody in the seminal plasma from patients with subacute gonococcal infection than in those with acute infection supports the above contention. The reason why some patients failed to have local antibody detected by these various immunological techniques is not clear, but it is possible to attribute this to the early treatment of the patients in this series and to the low protein content in some of these cervical fluids. However, the latter possibility could not be applied in all cases as some specimens with high total protein content also failed to have antibody detected by these methods. Because the positive fluorescence finding in seminal plasma and cervical fluid could be eliminated by previous absorption with non-pilated T4 gonococci, it appears that the antibody in these secretions is directed against the somatic antigens of $N$. gonorrhoeae. The inability to detect any HAI or OP activity in these IFA-positive secretions is also consistent with this notion, as both $\mathrm{HAI}$ and OP tests depend on specific interaction between pilated gonococci and anti-pilar antibodies (Punsalang and Sawyer, 1973). Anti-pilar antibodies may be initially present in these secretions but may have been absorbed out in vivo by pilated antigens in the secretions before collection and analysis. In the present study, the antibody response in secretions of patients with gonorrhoea has three characteristics that differ from the corresponding serum antibody response:

(1) Specificity of the antibody produced In secretion the antibody is mainly if not exclusively directed to the somatic antigens of $N$. gonorrhoeae, but in the serum it is mainly directed to the pilar antigens.

(2) Duration of the antibody response Antibody response in secretion is much shorter than in serum, as in most instances antibody could not be detected in these secretions more than a few days after treatment had been initiated, whereas in the serum it remained detectable for at least 2 to 3 weeks. This observation agrees with that of O'Reilly and others (1976) who studied only IgA antibody response and reported that local IgA antibody in the vaginal secretions of female 
patients with gonorrhoea declined rapidly to an undetectable level after treatment. Limited data available from this study suggest that IgG antibody in cervical fluid may persist longer than SIgA.

(3) Nature of antibody Although the predominant antibody to gonococcal antigens in secretions is IgG, IgA antibody is nevertheless detectable at higher frequency than would be expected from the analysis of serum IgA antibody. The difference between systemic and local IgA antibody would be more obvious if one took into account the difference in the absolute quantity of IgA in these two specimens.

The frequent occurrence of SIgA antibody to $N$. gonorrhoeae in secretions of the reproductive system and the lack of correlation between the antibody titres in the serum and in the secretions suggest that the immune system at this site is independent of serum antibody, a conclusion reached by O'Reilly and others (1976). The observation that local antibody and not serum antibody declined rapidly to an undetectable level after treatment is also consistent with the idea that these antibodies are locally synthesized. An indirect line of evidence for the existence of local antibody response in patients with gonorrhoea was obtained by Chipperfield and Evans (1972, 1975) who demonstrated that both the number of immunoglobulin-containing plasma cells in the endocervical tissues and the concentrations of IgA and IgG in the cervical mucus of patients with gonorrhoea were markedly elevated. Development of local antibodies in secretions of patients with other infections at this site has been reported (Ackers, Lumsden, Catterall, and Coyle, 1975; Waldman, Cruz, and Rowe, 1971).

The role of serum and/or secretory antibodies in protection against infection by $N$. gonorrhoeae is poorly defined. Recent observation on the effect of systemic immunization of chimpanzees with killed gonococci supports the idea that antibodies provide effective protection against experimental intraurethral infection by $N$. gonorrhoeae (Arko, Duncan, Brown, Peacock, and Tomizawa, 1976). However, the recent observation of O'Reilly and others (1976) that female patients with recurrent gonococcal cervicitis had high titres of serum antibody at the time of re-infection argues against the protective value of serum antibody. Although the present results as well as those of other workers (Kearns, O'Reilly, Lee, and Welch, 1973; O'Reilly and others, 1976) have demonstrated secretory antibody to $N$. gonorrhoeae in the secretions of male and female urogenital systems, its role in protection has never been clearly demonstrated. Our data, however, show that these antibodies neither inhibited the adherence of pilated gonococci to mammalian cells nor enhanced the phagocytosis of pilated gonococci by PMN. The observation that $N$. gonorrhoeae secretes extracellular enzymes capable of specifically destroying IgA (Plaut and others, 1975) is of interest and may also explain why re-infection can still occur in the presence of IgA antibody at this site. In this connection, IgG antibody may be more important than IgA antibody in local protection against gonococcal infection of the urogenital system.

A portion of this study was submitted by $P$. T. to the Faculty of Graduate Studies, Mahidol University, in partial fulfilment of the requirements for the Ph.D.

This investigation was supported in part by the National Research Council of Thailand and by the Rockefeller Foundation.

The authors are indebted to Drs. P. Matangkasombut and W. D. Sawyer for valuable suggestions and criticisms during the course of this study. The co-operation of Drs. M. Chulasamaya, K. Panikabutra, and W. Chavengsaksongkram in obtaining samples is greatly appreciated.

\section{References}

ACKers, W. H., Lumsden, W. H. R. Catterall, R. D., and CoYLe, R. (1975) Brit. F. vener. Dis., 51, 319

Arko, R. J., Duncan, W. P., Brown, W. J., Peacock, W. L., and Tomizawa, T. (1976) f. infect. Dis., 133, 441

BLAKE, M., and SwANSON, J. (1975) Infect. and Immun., 11, 1402

Buchanan, T. M., Swanson, J., Holmes, K. K., Kraus, S. J., and Gotschlich, E. C. (1973) f. clin. Invest., 52, 2896

Chipperfirld, E. J. and Evans, B. A. (1972) Clin. exp. Immunol., 11, 219

- (1975) Infect. and Immun., 11, 215

Cohen, I. R., KellogG, D. S., Jr., and Norins, L. C. (1969) Brit. F. vener. Dis., 45, 325

HerRmanN, W. P., and HermanN, G. (1969) Int. F. Fertil., 14, 211

JephCott, A. E., ReYN, A., and Birch-ANDERSEN, A. (1971) Acta path. microbiol. scand., 79, 437

KeARNS, D. H., O'Reilly, R. J., LeE, L., and Welch, B. G. (1973) f. infect. Dis., 127, 99

Kellogg, D. S., Jr., Peacock, W. L., Jr., Deacon, W. E., Brown, L., and PIRKLE, C. I. (1963) f. Bact., 85,1274

OfEK, I., BEACheY, E. H., and Bisno, A. L. (1974) $\mathcal{f}$. infect. Dis., 129, 310

O'ReILlY, R. J., LeE, L., and WelCH, B. G. (1976) Ibid., 133,113

LOWRY, O. H., Rosebrough, N. J., FARR, A. L., and RANDALI, R. J. (1951) f. biol. Chem., 193, 265

Masson, P. J., Heremans, J. F., and Ferin, J. (1969) Int. F. Fertil., 14, 1

Plaut, A. G., Gilbert, J. V., Artenstein, M. S., and CAPra, J. D. (1975) Science, 190, 1103

Punsalang, A. P., Jr., and Sawyer, W. D. (1973) Infect. and Immun., 8, 255

Swanson, J., KRAUS, S. J., and Gotschlich, E. C. (1971) f. $\exp$. Med., 134, 886

TJOKRONEgoro, A., and Sirisinha, S. (1975) Fertil. and Steril., 26, 413

WALdMan, R. H., Cruz, J. M., and Rowe, D. S. (1971) Clin. exp. Immunol., 10, 427

WelCH, B. G., and O'ReILly, R. J. (1973) F. infect. Dis., 127, 69 